\author{
Cadernos de \\ ESTUDOS LINGǘlSTICOS - (55.1), Campinas, Jan./Jun. 2013
}

\title{
FRAMES EM JOGO NA CONSTRUÇÃO DISCURSIVA E INTERATIVA DA REFERÊNCIA
}

\author{
EDWIGES MARIA MORATO ${ }^{1}$ \\ ANNA CHRISTINA BENTES ${ }^{2}$
}

\begin{abstract}
RESUMO
O objetivo deste artigo é refletir sobre aspectos referenciais e interacionais da noção de frame destacando, em meio a uma conversação desenvolvida por indivíduos afásicos e não afásicos, processos verbais e não verbais implicados na construção discursiva do referente. Podemos perceber, no fio do discurso e na organização sequencial do episódio conversacional analisado no escopo deste artigo, um interessante movimento de solidariedade entre gestão do tópico e construção referencial, pautada - entre outras coisas - pela conexão entre frames e pelas perspectivas assumidas intersubjetivamente pelos interactantes em relação ao referente em construção.
\end{abstract}

PALAVRAS-CHAVE: referenciação; frame; afasia.

\begin{abstract}
The objective of this paper is to discuss some referential and interactional aspects of the notion of frame.Considering a conversation developed by aphasic subjetcs and not aphasic subjects, we analyzed some multimodal and inferential processes involved in discursive construction of referents. We observed that sequential organization of conversational episode promotes an interesting movement of solidarity between topic management and referential construction. This movement is based - among otherthings - on the connections between frames established by interactants. In our view, these sociodiscursive processes point to the intersubjetive and dynamic nature of frames.

KEY-WORDS: referential processes; frame; aphasia.
\end{abstract}

\section{INTRODUÇÃO: HÁ VÁRIOS OBJETOS NUM SÓ OBJETO}

O objetivo deste artigo é refletir sobre aspectos referenciais e interacionais da noção de frame, por meio da análise dos recursos presentes em uma conversação desenvolvida por indivíduos afásicos ${ }^{3}$ e não afásicos, focalizando especialmente os processos verbais e não verbais implicados na construção discursiva e interativa do referente.

1. UNICAMP/CNPq, Campinas, Brasil. edwiges@iel.unicamp.br

2. UNICAMP/FAPESP, Campinas, Brasil. annabentes@yahoo.com.br

${ }^{3}$. As afasias são alterações de produção e compreensão da linguagem oral e/ou escrita que decorrem de lesões estruturais no Sistema Nervoso Central, causadas em geral por acidentes vasculares cerebrais e traumatismos cranioencefálicos. Podem ser associadas a sinais e sintomas neuropsicológicos, como hemiplegias, apraxias e agnosias. 
MORATO e BENTES - Frames em jogo na construção discursiva...

A refererenciação é aqui compreendida sob uma perspectiva sociocognitiva da construção do sentido, considerado por sua vez como um processo que está associado, entre outros fatores, à intersubjetividade e à perspectivização, nos termos assinalados por Tomasello (2003).

A partir da análise de um episódio extraído de um dos encontros do Centro de Convivência de Afásicos $(\mathrm{CCA})^{4}$, procuramos observar como diferentes frames - uns mais estáveis do que outros - interatuam na construção do desenvolvimento do tópico conversacional ${ }^{5}$.

O conjunto de frames ativados e mobilizados no decorrer do episódio revela a natureza colaborativa e sociocognitiva dos atos de referenciação, desenvolvidos por meio da mobilização de expressões linguísticas e da emergência de processos inferenciais, contextuais e multissemióticos (risos, expressão corporal, gestos, dêiticos espaciais, direcionamento do olhar, etc.). Tais processos, como observam Morato et al. (2012), podem ser entendidos como construtores de referência, pois dizem respeito à "construção, indução ou ativação de referentes no processo textual-discursivo que envolve atenção cognitiva conjunta dos interlocutores e processamento local". (MARCUSCHI, 2005, p.54)

A gestão e o desenvolvimento do tópico, por seu turno, estão intimamente associados à estruturação da rede de operações referenciais desenvolvidas a partir da ativação e da conexão de diferentes frames, evocados ou elaborados tanto por unidades lexicais, quanto por construções textuais.

De maneira específica pretendemos, no contexto de tais observações, analisar a maneira pela qual um subtópico introduzido na conversação - o principado de Mônaco - se organiza enquanto objeto de discurso ${ }^{6}$, instaurando/mobilizando frames e (re)organizando o desenvolvimento do tópico discursivo. Tais frames se constituem como sistemas linguístico-conceptuais baseados em conhecimentos de diversas ordens, apreendidos pela via da interiorização das experiências sociais, compartilhados ou não pelos indivíduos em interação.

O principado de Mônaco, cumpre observar, estabiliza-se na conversação como um supertópico (JUBRAN, 2006; BENTES e FERRARI, 2011) a partir do interesse que desperta quando da introdução na conversação, feita por um dos

4. O Centro de Convivência de Afásicos, localizado no Instituto de Estudos da Linguagem da Universidade Estadual de Campinas (UNICAMP), pode ser definido como um espaço de interação entre pessoas afásicas e não afásicas cujo objetivo é desenvolver estudos linguísticos e neurolinguísticos, bem como garantir às pessoas afásicas efeitos terapêuticos e sociais possibilitados por um conjunto variado de experiências interacionais cotidianas (MORATO et al., 2002). Para maiores informações: http://cogites.iel.unicamp.br/p/atividades-no-cca.html

${ }^{5}$. A concepção de tópico que invocamos é aquela que se define como "um conjunto de referentes explícitos ou inferiveis concernentes entre si e em relevância num determinado ponto da mensagem" (Jubran et al. 1992, p.361).

${ }^{6}$. Autores como Mondada e Dubois (1995) ou Berrendoner e Reichler-Béguelin (1995), dentre vários outros, utilizam a noção de objeto de discurso para postular que os referentes são dinâmica e sócio-discursivamente constituídos, caracterizando-se como instáveis, flexíveis e não fixados de forma prévia à interação. Ainda que os dois conceitos, referente e objeto de discurso, sejam tomados de forma indistinta, mantemos aqui uma diferença entre eles, baseada no caráter de "work in process" dos objetos de discurso, referentes instáveis e em construção na interação. 
participantes afásicos, da notícia sobre o falecimento do Príncipe Rainier III, ocorrido em 06 de abril de 2005 (MORATO et al., 2012).

De maneira muito interessante, como veremos, Mônaco emerge na conversação como esse lócus que abriga distintas compreensões da metáfora do paraíso: terreal (associadas à beleza geográfica, à presença da nobreza, à delimitação territorial, aos prazeres mundanos, à elegância do estilo de vida de seus habitantes) e fiscal (associadas à pouca ou nenhuma tributação fiscal, à facilitação de aplicação de capitais estrangeiros, à ilegalidade ou fraude financeira, à origem desconhecida de capitais depositados em determinados estados ou territórios, à evasão tributária, à legislação baseada na proteção da identidade dos investidores, à neutralidade política de estados ou territórios considerados paraísos fiscais). Esse contexto referencial de paraíso (terreal, fiscal) faz-nos lembrar a frase que expressa um princípio de transformação dialética na peça teatral "Horácios e Curiácios", de Bertolt Brecht: "há vários objetos num só objeto.

Contudo, se os primeiros frames evocados e compartilhados quase que imediatamente pelos interactantes a partir de seus conhecimentos prévios e dispostos na memória cultural referem-se a elementos mais estáveis, incorporados, como o de beleza geográfica e o de um certo estilo de vida característico de Mônaco, os segundos, que se referem principalmente à política de sigilo fiscal, à neutralidade (ou "irrelevância", como diz uma das participantes da conversação aqui focalizada) política, ou à pouca ou nenhuma obrigação fiscal são construídos de maneira mais complexa na interação; não sendo inteiramente compartilhados, são construídos in situ de maneira colaborativa e largamente inferencial.

Frame e referenciação tornam-se fenômenos essencialmente interrelacionados em função do lócus privilegiado em que emergem e se constituem: linguagem e cognição em interação. Assim sendo, parece-nos promissora a proposta de se pensar o frame enquanto "flexibilidade discursiva e sociocognitiva" (COULSON, 2001).

\section{APROFUNDANDO A PROBLEMATIZAÇÃO}

Como já anunciamos na seção anterior, no episódio linguístico-interacional que focalizamos neste artigo o referente Mônaco é emoldurado em termos sociocognitivos de diversas maneiras, sendo tomado como paraíso terreal, mas também como paraíso fiscal, construção metafórica bastante complexa.

A expressão paraíso fiscal é, em geral, associada a lugares ou situações conhecidas por certas práticas contraventoras ligadas especialmente à lavagem de dinheiro e a fraudes financeiras, sendo seus beneficiários sonegadores e outros criminosos; tomado em um sentido mais específico, o sintagma metafórico pode dizer respeito a "países ou dependências que tributam a renda com alíquota inferior a 20\%", como entende a Receita Federal. Esta segunda acepção, defendida pelos que salientam, por exemplo, a legalidade de empresas offshores, não associa diretamente os paraísos fiscais a situações ou práticas fraudulentas e a crimes variados a elas vinculados. 
MORATO e BENTES - Frames em jogo na construção discursiva...

Segundo Fillmore (1985), lembremos, frames são modelos semânticos de representação da compreensão do sentido. Tais modelos podem ser considerados, em sua perspectiva, "ferramentas" com as quais organizarmos os sentidos ativados e construídos nos processos contextualizados de produção e intepretação.

Também na linhagem de cunho cognitivo, Lakoff (2004) assinala, por sua vez, que os frames "moldam" a maneira como concebemos pragmaticamente o mundo, enquanto van Dijk (1992) utiliza a noção no estudo do processamento do discurso, relacionando-a principalmente com os modelos estratégicos de modelagem, armazenamento e ativação seletiva da memória.

Aprofundando um pouco mais os aspectos pragmáticos e interacionais da noção, Gumperz (1982) assinala, com muita propriedade, que frames são conceitos relacionais e não mera sequência de eventos. Além disso, são altamente dependentes do contexto. Essa posição também pode ser encontrada no coração dos trabalhos de Goffman (1974) e de Tannen e Wallat (1985).

Uma das questões de fundo que se mostram interessantes para a discussão que se projeta aqui é: quais processos se encontrariam implicados na interação entre frames e construção referencial? Com base no que acontece no episódio analisado no escopo deste artigo, podemos postular tanto a elaboração/emergência de expressões referenciais típicas, quanto as predicações, as inferências de variadas naturezas, a emergência de semioses não verbais, etc.

Outra questão que nos interessa destacar é: como aparecem e se mantêm os frames em meio ao processamento textual-interativo da conversação em foco? Com base no episódio focalizado, podemos postular que frames heterogêneos atuam na constituição e no desenvolvimento do tópico discursivo, bem como nas orientações argumentativas que se constroem no desenrolar da conversação.

Uma terceira questão vale a pena ser colocada no contexto da discussão que se projeta no âmbito deste artigo: como se dá o agenciamento dos frames no decurso da interação? Para responder a esta questão, parece-nos necessário focalizar a organização ou a relação social em que os sujeitos estão mergulhados ao produzirem significações.

Tendo em vista o exposto, os frames podem ser entendidos de forma relacional, isto é, como enquadres cognitivos que se forjam a partir não apenas dos esquemas de conhecimento ativados e elaborados conjuntamente pelos interactantes, como também a partir do enquadramento social dos participantes da conversação e do contexto interacional local em que estão imersos.

A construção do referente Mônaco durante a conversação, seja como paraíso terreal ("paraíso mítico posicionado na terra"), seja como paraíso fiscal ("lugar ideal para a aplicação, facilitação ou fraude de capitais"), se dá a partir da ativação e a (re)organização de determinados frames e de expressões referenciais associadas a essas metáforas. Como veremos, diferentes frames parecem atuar, por meios de formas nominais e por processos multissemióticos variados (risos, expressão gestual, direcionamento do olhar, etc.) na maneira pela qual o objeto de discurso Mônaco é construído e categorizado na interação. Podemos perceber, no fio do discurso (FRANÇOIS, 1993) e na organização sequencial do episódio, um interessante movimento de solidariedade recíproca entre gestão do tópico e 
construção referencial, pautada - entre outras coisas - pela conexão entre frames $e$ pelas perspectivas assumidas intersubjetivamente pelos interactantes em relação ao referente Mônaco. Esse movimento, a nosso ver, assinala o caráter dinâmico, situado e discursivo do frame.

\section{CONTEXTUALIZANDO O EPISÓDIO CONVERSACIONAL}

O episódio analisado, que integra o corpus de uma pesquisa coletiva financiada pelo $\mathrm{CNPq}^{7}$ e finalizada em 2012 (cf. MORATO et al, 2012), foi extraído de um dos encontros do CCA, ocorrido em 2005. Trata-se, na realidade, de um longo episódio que integra o corpus da pesquisa acima mencionada, cujos resultados foram relatados em um artigo publicado em 2012 na revista Linguagem em (Dis)curso. O sistema de notação utilizado na pesquisa, que pode ser visto ao final deste artigo, leva em conta uma adaptação da proposta de Mondada (2004) baseada, por sua vez, no sistema de transcrição de Jefferson (1984).

Estão presentes no episódio interacional os participantes afásicos SP e MS e as participantes afásicas ED, SI, MN e NS, além das participantes não afásicas EM, HM e JC.

No contexto do trecho selecionado para a análise, esses participantes do CCA trocam informações e tecem comentários sobre o principado de Mônaco, tópico que se estabiliza após SP ter introduzido na conversação a notícia do falecimento do príncipe Rainier III. Esse tópico inicial, isto é, o falecimento de Rainier III, dá margens ao desenvolvimento de subtópicos, como o que gira em torno de Grace Kelly (atriz norte-americana com quem fora casado o falecido), do sistema de governo de Mônaco, das impressões de SP, um senhor francês, sobre a topografia do principado.

Transformado no decurso da interação em supertópico em função do acúmulo de informações variadas presentes na memória coletiva dos participantes do grupo, Mônaco também é elaborado, na conversação, como um objeto de discurso, fortemente ancorado na ativação e no reconhecimento de determinados frames e enquadres cognitivos (MORATO et al., 2012).

Por meio de diferentes processos referenciais, os interactantes aventam as propriedades ou características desse referente em construção, fazendo alusões de forma verbal e não verbal - ao pequeno tamanho do principado, à sua beleza geográfica, à sua identificação como um lugar de circulação da elite europeia, à legalidade dos cassinos que lá se encontram, ao alto custo de vida, ao fato de ter sido a residência do piloto brasileiro Ayrton Senna, às corridas de Fórmula 1, a figuras da política nacional que supostamente teriam grandes somas de dinheiro depositadas em bancos monegalescos. Esses elementos são fundamentais na orientação argumentativa, na coerência discursiva e na estruturação e desenvolvimento do tópico conversacional (cf. MORATO et al., 2012).

\footnotetext{
7. "Processos referenciais implícitos na conversação entre sujeitos afásicos e não-afásicos" (CNPq - Processo 400751/2010-0).
} 
MORATO e BENTES - Frames em jogo na construção discursiva...

Além de processos multissemióticos, as chamadas âncoras textuais ${ }^{8}$ atuam não apenas nos atos de referenciação, como também na identificação dos frames em jogo na conversação.

\section{O frame de paraíso (terreal)}

Vejamos as expressões referenciais com as quais o objeto de discurso Mônaco será construído ao longo do episódio. Inicialmente, ele é designado como estado por meio de uma referenciação subespecificada, a partir da referência ao falecido, o príncipe Rainier III (1925 JC outro chefe de estado né $/{ }^{\circ} / 1926 \mathrm{EM}$ outro chefe de esta:do $\left.\backslash\right)$. A pouca relevância desse estado será assinalada por JC, que procede a uma recategorização do referente por meio de uma predicação (1928 JC ${ }^{\circ}$ menos (notório) ${ }^{\circ}$ ); SP, um senhor afásico, especifica o referente ao nomeá-lo mais adiante (1934 SP 'é: : : \ $(0,7)$ mônaco $\left.{ }^{\circ}>\right)$. Por meio de uma construção anafórica, EM agrega informações sobre Mônaco, definindo-o política e geograficamente por meio de uma referenciação dêitica que o instancia em uma espacialidade discursiva:

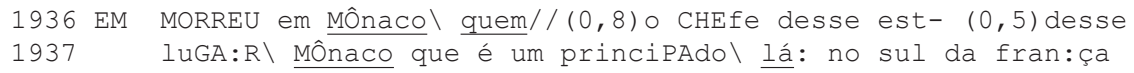

Identificado um pouco mais o referente, os interactantes elencam suas características por meio de distintas formas designativas e de acordo com as informações e perspectivas que estabelecem em torno dele. EM, por exemplo, expressa com um articulador textual uma qualidade da atividade econômica ligada ao principado, a ser retomada de outro modo na conversação (1939 EM que tem os cassi:nos de mô::naco:). Na sequência, repetindo SP, MS reitera a informação sobre a pequena dimensão territorial de Mônaco (1940 MS + piqui: nhoo $\backslash+$ ). Por meio de uma anáfora indireta, "Grace Kelly", ED evoca um fato célebre da vida do falecido: o casamento do príncipe com uma famosa atriz norte-americana. Esta informação provoca a emergência da predicação observada no turno de EM (1947 EM É: \ ele foi [caSA:do: \]). Observa-se aqui a remissão a um fato que, cumpre observar, também compõe o frame mítico associado a Mônaco.

Após um momento digressivo em torno da retomada das informações de que o grupo dispõe sobre o príncipe Rainier III (não muitas, na verdade, se comparadas com as informações que os interactantes dispõem sobre o principado), EM retoma o tópico instaurado em momentos anteriores - Mônaco - ao qual aderem os demais. EM assinala nesse momento a baixa densidade do principado e o fato de ser "muito rico e pequeno" (1970 EM [muito RICO e muito peque:no $\backslash](0,5))$.

${ }^{8}$. Não se realizando apenas sob a forma de expressões linguísticas, a referenciação não deixa de ser, de algum modo, constituída por "âncoras" semânticas, cognitivas e textuais. (KOCH, 2004; MARCUSCHI, 2005). 
O comentário de EM suscita risos, expressões faciais de perplexidade e gestos de confirmação com a cabeça e comentários feitos de maneira simultânea por vários interactantes, o que demonstra que boa parte dos presentes já detém certas informações sobre Mônaco e assume avaliações comuns em relação às implicações que delas vão emergindo e que vão sendo associadas com base em domínios semânticos variados de forma colaborativa no decurso da interação (como a relação entre o tamanho diminuto do principado e sua densidade populacional, a riqueza de seus habitantes e sua topografia privilegiada, a presença dos cassinos e a ilegalidade observada em certos países ou territórios). Abaixo, podemos observar que SP se vale de um gesto reconhecido pelos demais como alusivo a dinheiro para se referir a Mônaco.

1976 SP lá: lá: 0: ]

1977 ((esfregando dois dedos da mão esquerda))

Os interactantes voltam a agregar informações de que dispõem sobre Mônaco, destacando seu sistema de governo (2029 HM 'uma monarquia ${ }^{\circ}$ ), sua beleza geográfica (2043 SP li:ndo 1 lindo $\quad\left[{ }^{\circ} 1\right.$ indo $\backslash$ lindo $\left.{ }^{\circ}\right]$ ) e sua topografia privilegiada (2032 HM fica entre a: iTÁlia e a frança ali né/), elementos estes associados ao frame de paraíso terreal.

\section{Do paraíso terreal e do paraíso fiscal}

A emergência do frame paraíso fiscal na conversação parece resultar da confluência de uma série de proposições e construções linguístico-conceptuais acerca desse frame e envolve tanto a recuperação de certas informações, mais gerais, culturalmente construídas (como a ilegalidade associada aos jogos, a ausência de uma economia forte, a beleza geográfica, o estilo de vida glamouroso, a proverbial neutralidade política), quanto a emergência de informações mais específicas, estabelecidas sem aparente conexão com a construção referencial que até então se esboçava, constituída pelos sentidos sociais relativos à pouca relevância política, à estratificação socioeconômica, à política de anonimato dos bancos, aos esquemas de fraude financeira.

Vários são os conhecimentos de mundo que giram em torno da expressão nominal paraíso fiscal, enunciada meta-enunciativamente por EM em dado momento do episódio (2139 EM [como um PARA] ÍSO FISCA:L).

Trata-se de uma expressão referencial que emerge, como se verá no fragmento abaixo, em um processo anafórico que sumariza uma série de informações e proposições processadas de modo largamente inferencial pelos interactantes. É MS, vale notar, quem promove uma inflexão argumentativa em relação à forma como a referência a Mônaco vinha sendo estabelecida:

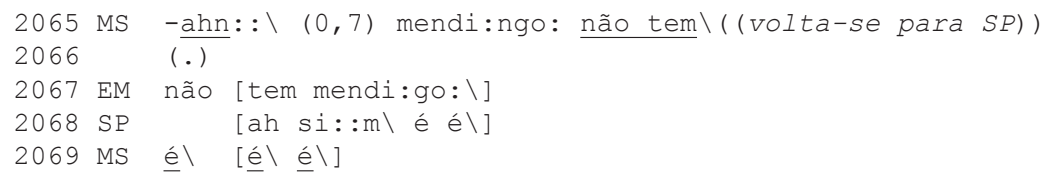


MORATO e BENTES - Frames em jogo na construção discursiva...

Por inferência contextual, a referência de Mônaco como paraíso fiscal, mais explícita posteriormente, vai se estabelecendo aqui.

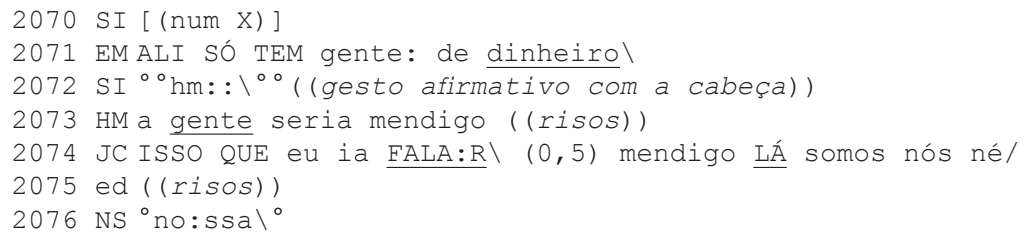

Ainda que o referente Mônaco não tenha sido explicitado neste momento do episódio, ele é inferido com base em informações e inferências variadas, alusivas tanto à ausência de mendigo, quanto de integrantes da classe média no principado, como os participantes do CCA, referência aqui subespecificada: a gente seria mendi go. Frente a esse enunciado, JC procede a um comentário à linha 2074 no qual podemos observar uma referênciação dêitica, provocando o riso cúmplice dos demais: mendigo LÁ somos nós né/.

A construção referencial de Mônaco como região de circulação de elite econômica também se constrói a partir da remissão a um dêitico espacial metafórico enfatizado prosodicamente por EM à linha 2071: ALI só tem gente de dinheiro. A referenciação dêitica, vale dizer, atua em vários momentos do episódio conversacional.

Na sequência, o grupo fala sobre o piloto brasileiro Ayrton Senna, famoso morador de Mônaco, e comenta a respeito das contas bancárias sigilosas de algumas celebridades.

SP explica, abaixo, o esquema de depósitos bancários sigilosos, e uma primeira interpretação de EM (2135 EM ah: : \ JOGA nos cassinos \ é isso//), com base na ambiguidade do verbo jogar, é corrigida por ele. A expressão referencial que evoca o frame de corrupção se ancora nos fragmentos anteriores do episódio e emerge aqui de forma modalizada no turno de EM ("como um paraíso fiscal").

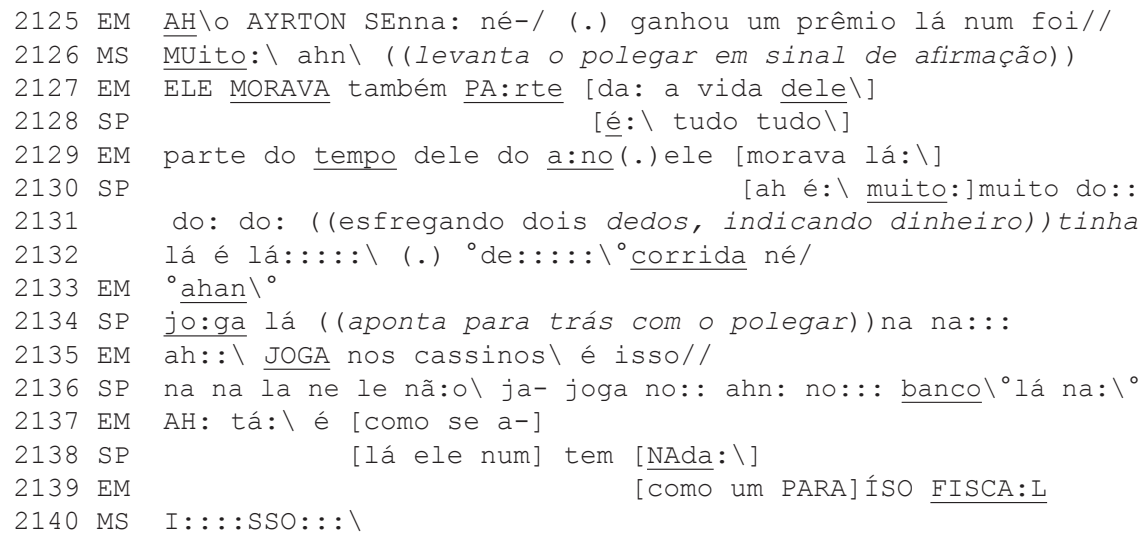


A partir da evocação da expressão nominal paraíso fiscal, outras informações associadas a Mônaco emergem na conversação, por meio de variados processos referenciais: elevadas somas depositadas de forma sigilosas em instituições financeiras localizadas no principado, ausência de pagamento de impostos e associação de Mônaco com outros conhecidos paraísos fiscais, como a Suíça e as Ilhas Caimã.

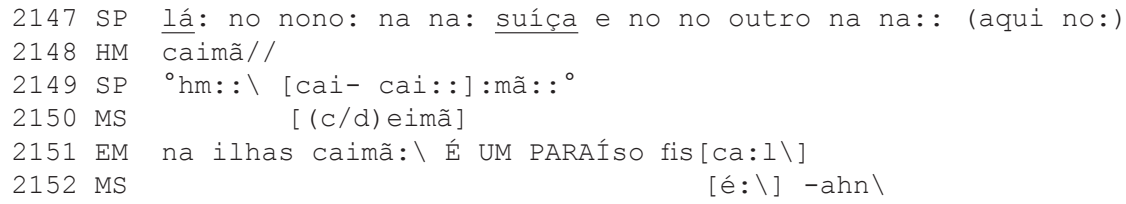

A construção referencial de Mônaco contém (também) os elementos acima, e o frame de corrupção associado ao de paraíso fiscal faz o grupo evocar casos de celebridades e políticos da cena nacional e internacional acusados de crime fiscal e evasão de capitais.

A remissão a esses casos é interessante para a consolidação de um aspecto importante do frame de paraíso fiscal: a motivação da fraude fiscal praticada por grupos financeiros, empresas e indivíduos de diversas nacionalidades.

No fragmento abaixo, ED questiona o motivo que leva as pessoas a enviar dinheiro do Brasil para o Exterior. EM, JC, SP e MS reagem de diversas formas ao questionamento de ED: uns riem, outros aludem de forma irônica a explicações históricas remotas e complexas sobre a corrupção no País.

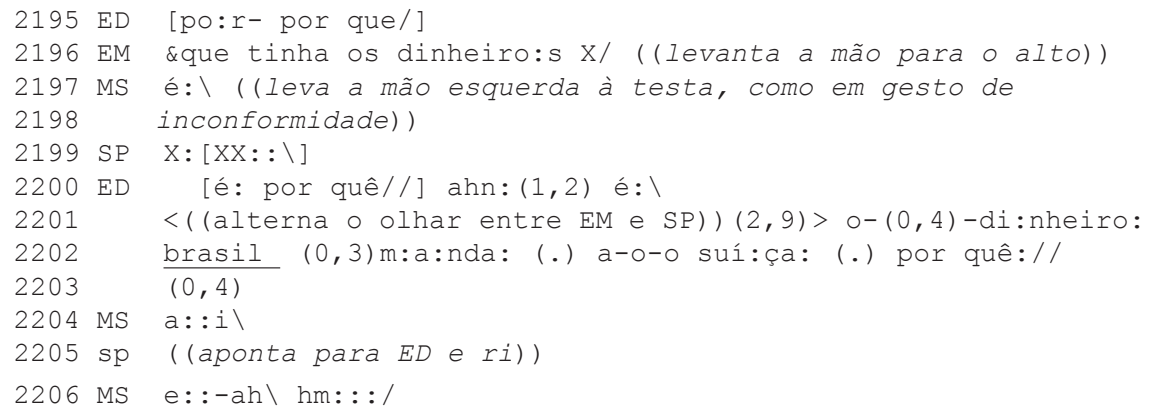

Interpelando MN, EM lhe pede para responder à pergunta de ED. À linha 2236, por inferência contextual, $\mathrm{MN}$ é direta na formulação de sua resposta, que tem o apoio de NS, HM e SP.

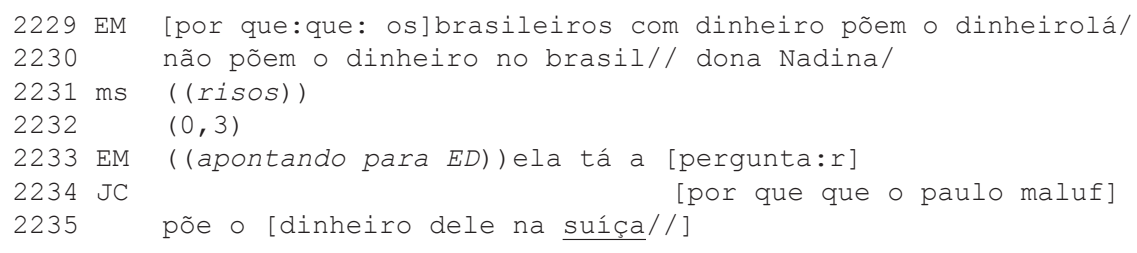


MORATO e BENTES - Frames em jogo na construção discursiva...

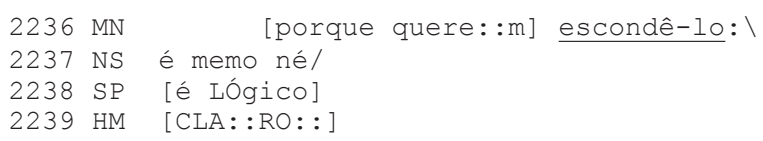

Na sequência desse fragmento, os participantes se concentram em explicitar o funcionamento e as características da fraude financeira e da política de anonimato praticada por estados e territórios considerados paraísos fiscais. Nesse contexto JC, EM, HM e SP passam a qualificar a Suíça como paraíso fiscal, como já havia sido feito em relação a Mônaco.

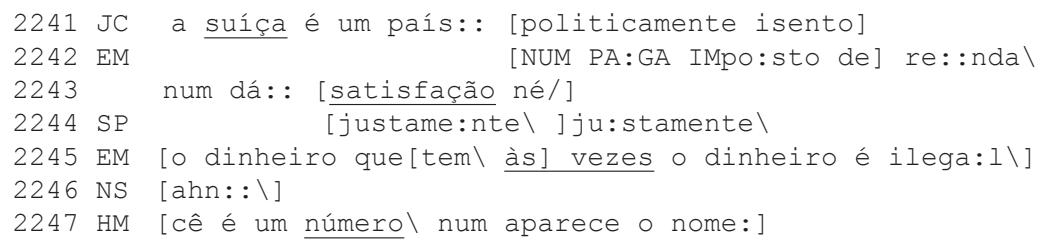

ED, no fragmento final do episódio, a partir de várias inferências permitidas pelas contribuições dos demais participantes e também com base em seu conhecimento de mundo, parece finalmente compreender as razões que levam indivíduos suspeitos de sonegação a enviarem seu dinheiro para o Exterior nas condições permitidas por paraísos fiscais. Tendo realizado várias inferências (textuais e contextuais) que lhe permitiram mobilizar conhecimentos necessários para a construção de um enquadre cognitivo de corrupção político-financeira ligada aos paraísos fiscais (como os eventos mencionados pelos interactantes), ED produz na última troca de turno do episódio um comentário interjectivo com o qual deplora as ações fraudulentas como as descritas pelos demais (2319 ED ô vi:da:), sendo nisso apoiada por NS (2320 NS é isso mesmo $)$.

\section{COMENTÁRIOS FINAIS}

A análise desse episódio revela que tanto os interactantes afásicos, quanto os não afásicos participam da gestão do tópico, envolvendo-se na dinâmica de turnos, na construção conjunta dos sentidos e na negociação de frames e de atividades de referenciação.

Com isso, reforçamos os achados empíricos observados em pesquisas que vimos desenvolvendo sobre aspectos linguísticos e cognitivos no contexto das afasias: problemas metalinguísticos stricto sensu (como as dificuldades de seleção lexical ou de processamento de categorias gramaticais, por exemplo) não destroem a capacidade de operar com elementos referenciais; no caso das afasias, o sujeito costumeiramente enfrenta no campo mesmo da linguagem suas dificuldades metalinguísticas (por meio e em meio a reparos, reformulações, riqueza prosódica, repetições, hesitações, utilização de promptings orais do interlocutor, checagem de intenção comunicativa ou de informação lexical, reformulações parafrásticas, 
construções explicativas, etc.), lançando mão, além disso, de semioses não verbais (como gestos, direcionamento do olhar, postura corporal, etc.) que atuam de maneira solidária à linguagem na configuração ou na interpretação de referentes textuais (cf. MORATO et al., 2012).

Como pudemos observar no episódio discutido acima, vários processos referenciais, verbais e não verbais, são necessários à construção e evocação de esquemas mais ou menos prototípicos de conhecimento, bem como de estruturas de expectativa relativas aos conhecimentos, pressupostos ou construídos in situ pelos interactantes.

A construção referencial de Mônaco ativa na conversação vários elementos associados ao paradisíaco principado, identificado não apenas como paraiso terreal, como também com paraíso fiscal. Várias expressões referenciais entram em cena na construção desse objeto de discurso, Mônaco, destacando sua condição de paraíso terreal (baseada em sua beleza geográfica, nas condições sociais de seus habitantes, em sua topografia minúscula cercada de outras regiões menos afortunadas, em sua abundância econômica, em sua harmonia e neutralidade política) e fiscal (baseada na legalidade de jogos de azar, na facilitação de aplicação de capitais, na sonegação de impostos, na política de sigilo fiscal). Tais elementos, que emergem de forma colaborativa na conversação, constituem o referente a partir de enquadres cognitivos distintos.

O objeto de discurso Mônaco é construído a partir da evocação de frames de paraíso terreal e de paraíso fiscal. Consideradas a partir de um determinado universo discursivo, tais metáforas constroem uma conceptualização na qual ambas podem ser tomadas como expressão de um lugar ou situação idealizada pela lógica capitalista da abundância, beleza e harmonia para aqueles poucos que também se encontram na condição de se serem livres dos impostos e do labor. Os frames (re)tomados na interação, como procuramos apontar, são tributários de operações referenciais largamente implícitas colocadas e construídas na cena enunciativa a partir de pressupostos compartilhados ou apenas presumidos.

As práticas linguísticas e interacionais podem ser vistas como um lócus interessante para a observação de uma relação mutuamente constitutiva entre conceptualização e interação. Como pondera Morato (2010, p.101), a propósito dessa interrelação:

A noção de frame parece ter a ver, pois, assim como a noção de contexto, com um estado de coisas que em parte está organizado a priori, e em parte está associado a uma significação que emerge de sua própria organização (cf. Hanks, 2008).

\section{REFERÊNCIAS BIBLIOGRÁFICAS}

BENTES, A. C.; FERRARI, N. (2011) "E agora o assunto é trabalho": organização da experiência social, categorização e produção de sentidos no programa manos e minas. Revista Diadorim. Volume 10: 75-93, Dez.

COULSON, S. (2001). Semantic Leaps: frame shifting and conceptual blending in meaning construction. Cambridge: Cambridge University Press. 
MORATO e BENTES - Frames em jogo na construção discursiva...

FILLMORE, C. (1985). Frames and the semantics of understanding. Quaderni di Semantica, Vol. 6.2: 222-254.

FRANÇOIS, F. (1993). Pratiques de l'oral. Dialogue, jeu et variations des figures du sens. Paris: Nathan Pédagogie.

GOFFMAN, E. (1974). Frame analysis. New York: Harper \& Row.

GUMPERZ, J. (2002). Convenções de contextualização. In: RIBEIRO, B. T. e GARCEZ, P. M. (Orgs). Sociolinguística Interacional. São Paulo: Loyola. p.149-182. (original de 1982)

JEFFERSON, G. (1984). Transcription Notation. In: J. ATKINSON; J. HERITAGE Eds). Structures of Social Interaction, N. Y: Cambridge University Press, pp. ix-xvi.

JUBRAN, C.C.A.S. (2006). Revisitando a noção de tópico discursivo. Cadernos de Estudos Lingüísticos, 48(1):33-41.

JUBRAN, C.C.A.S.; URBANO, H. et al. (1992). Organização tópica da conversação. In: ILARI, R. (Org.). Gramática do Português Falado Campinas: Editora da Unicamp Vol.II - Níveis de análise linguística. p.357-439.

LAKOFF, G. (2004). Don't Think of an Elephant!: know your values and frame the debate. Vermont: Chelsea Green Publishing.

KOCH, I.G.V. (2004). Introdução à Lingüistica Textual. São Paulo: Martins Fontes.

MARCUSCHI, L. A. (2005). Anáfora indireta: o barco textual e suas âncoras. In: KOCH, I. V.; MORATO, E.M.; BENTES, A. C. Referenciação e Discurso. São Paulo: Contexto, p. 53-101.

MONDADA, L.; DUBOIS, D. (1995). Construction des objets de discours et catégorisation: une approche des processus de référentiation. TRANEL, 23: 273-305.

. (2004). Temporalité, séquentialité et multimodalité au fondement de l'organisation de l'interaction: Le pointage comme pratique de prise du tour. In: FILLIETTAZ, L. (Ed.). Les modèles du discours face au concept d'action, Cahiers de Linguistique Française, 26:269-292.

MORATO, E.M; BENTES, A.C.; TUBERO, A.L.; MACEDO, H.O.; CAZELATO, S.O.; MIRA, C.C.R.; MARTINS, E.M. (2012). Processos implícitos, contextuais e multimodais na construção referencial em conversações entre afásicos e não afásicos: relato de pesquisa. Linguagem em Dis(curso), 12(3):711-742.

MORATO, E.M. (2010) A noção de frame no contexto neurolingüístico: o que ela é capaz de explicar? Cadernos de Letras da UFF 4: 93-113.

. et. al. (2002). Sobre as afasias e os afásicos - subsídios teóricos e práticos elaborados pelo Centro de Convivência de Afásicos (Universidade Estadual de Campinas). Campinas: Unicamp.

TANNEN, D; WALLAT, C. (1998). Enquadres interativos e esquemas de conhecimento em Interação: Exemplos de um exame/consulta médica. In: RIBEIRO, B. e GARCEZ, P. (Org.). Sociolingüística Interacional. Porto Alegre: Age, 120-14. (original de 1985)

TOMASELLO, M. (2003). Origens culturais da aquisição do conhecimento humano. São Paulo: Martins Fontes. (original de 1999)

VAN DIJK, T. (1992). Cognição, Discurso e Interação. São Paulo: Contexto. 
ANEXO

Informações gerais sobre o sistema de notação

a) as iniciais do nome e do sobrenome são utilizadas para a identificação dos participantes;

b) a transcrição é apresentada em formato lista;

c) o segmento sublinhado marca uma enfase particular dada à palavra

d) sublinhada ou parte dela;

e) letras MAIÚSCULAS marcam um alto volume da voz;

f) os símbolos ${ }^{\circ}$ marcam um volume baixo, ou murmúrio de voz

\subsection{Fenômenos sequenciais:}

[ : inicio de overlap (sobreposição de vozes)

$=$ : latching (simultaneidade de vozes)

\& : continuação do turno de fala pelo mesmo locutor, para além da interrupção de linha da transcrição provocada pela introdução de overlap de outro locutor.

\subsection{Pausas}

- (micro pausas, inferiores a 0,3 segundos, não medidas)

$(x, x$ s) pausas medidas com ajuda do Felt Tip Sound Studio 2.1.1

\subsection{Fenômenos segmentais}

: alogamento silábico

- palavra truncada, esboçada

- hmarca uma aspuração do locutor

H marca uma expiração do locutor.

\section{4 Prosódia}

/e \ marcam as intonações crescentes e decrescentes

// e $\backslash \backslash$ marcam marcam as intonações crescentes e decrescentes fortemente pronunciadas

\subsection{Descrições e comentários}

((risos)), entre parênteses, marcam os comentários do transcritor ou os fenômenos não transcritos

<> delimita o segmento ao qual se refere a descrição entre parênteses

\subsection{Incertezas do transcritor}

SI -segmento ininteligível

(hipótese) um segmento ouvido pelo transcritor, mas incerto

(hipótese 1 e 2) marcam duas possíveis variáveis (multitranscrição)

2.7 Descrição de ações (gestos, movimentos, olhares, posturas) * * delimitam as ações descritas (na linha que se segue) e a relação à temporalidade da fala (outros símbolos, como + + , podem ser utilizados quando trata-se de diversos fenômenos ou locutores) -----indica a sequência da ação

---->indica que a ação descrita continua na linha seguinte ou várias linhas seguintes

--->* indica o fim da ação descrita que continua em várias linhas 
Ficha técnica

Divulgação Publicações IEL-UNICAMP

Montagem Publicações IEL

Editoração In Design CS5

Formato $16 \times 23 \mathrm{~cm}$

Mancha $12 \times 19 \mathrm{~cm}$

Tipologia Time new roman

Papel Miolo: pólen soft $75 \mathrm{~g} / \mathrm{m}$

Capa: cartão supremo $250 \mathrm{~g} / \mathrm{m}$

Impressão e acabamento Oficinas Gráficas da UNICAMP

Numero de páginas 138 páginas

Tiragem 300 exemplares 